\title{
On the counter-radiation of the atmosphere
}

\author{
ANDERS ANGSTRÖM
}

Translated from German and edited by Esther VOLKEN ${ }^{1}$, STEFAN BRÖNNIMANN ${ }^{2,3 *}$ and ROLF PHILIPONA ${ }^{4}$

${ }^{1}$ Proclim, Bern, Switzerland

${ }^{2}$ Oeschger Centre for Climate Change Research, University of Bern, Switzerland

${ }^{3}$ Institute of Geography, University of Bern, Switzerland

${ }^{4}$ Federal Office of Meteorology and Climatology, MeteoSwiss, Payerne, Switzerland

Original citation:

ANGSTRÖM, A., 1916: Über die Gegenstrahlung der Atmosphäre. - Meteorol. Z. 33, 529-538.

Suggested citation:

ANGSTRÖM, A. 1916: Über die Gegenstrahlung der Atmosphäre (On the counter-radiation of the atmosphere). - Meteorol. Z. 33, 529-538 (translated and edited by VOLKEN, E., S. BRÖNNIMANN, R. PHILIPONA). - Meteorol. Z. 22 (2013), 761-769 (published online January 2014).

\begin{abstract}
This paper is the edited translation of the paper by ANDERS ANGSTRÖM "Über die Gegenstrahlung der Atmosphäre" (On the counter-radiation of the atmosphere) that was published 1916 in the Meteorologische Zeitschrift 33, 529-538.
\end{abstract}

Keywords: Radiation, downward longwave radiation, history of meteorology.

Superscript numbers indicate original footnotes (translated at the bottom of the page), E. . . numbers indicate editorial endnotes (at the end of the article), square brackets [] indicate editorial comments in the text (except in Tables 1 and 6, where square brackets were used in the original text).

1. Recently, questions regarding the radiation of the atmosphere gained interest due to the works by W. J. HUMPHREYS $^{\mathrm{E} 1}$ and $\mathrm{GOLD}^{\mathrm{E} 1}$, and in particular due to the theoretical study by R. EMDEN ${ }^{\mathrm{El}}$ "Über Strahlungsgleichgewicht und atmosphärische Strahlung" [,On the radiation balance and atmospheric radiation"]. ${ }^{1}$ EMDEN shows in his work, to which I will return later, how the temperature in the upper inversion layer can be calculated based on the magnitude of the solar constant, the Earth's albedo, and the transparency of the atmosphere for terrestrial radiation, making simple assumptions concerning the dependence of the radiation coefficient of the atmosphere on its water vapour content. The procedure is simplified by distinguishing between longwave and shortwave radiation, for which the calculations are carried out based on the assumption of a standard value of absorption and emission coefficient. Under these assumptions, EMDEN calculates, furthermore, the temperature at the Earth's surface, the temperature gradient in the layers where convection stops, and

\footnotetext{
${ }^{*}$ Corresponding author: Stefan Brönnimann, University of Bern, Institute of Geography, Hallerstrasse 12, 3012 Bern, Switzerland, e-mail: stefan.broennimann@giub.unibe.ch

${ }^{1}$ Sitzber. D. Kgl. Bayer. Akad. D. Wiss., Math-Phys. K1. 1913, p. 55. ${ }^{\text {E1 }}$
}

the actual radiation temperature of the Earth. The experimental basis is in some parts very uncertain, which is also emphasized by EMDEN. This is particularly true for the value of the albedo of the Earth and the absorption coefficient of the atmosphere for longwave radiation.

2. On my excursions to Algeria (1912) and California (1913), I measured the effective terrestrial radiation ${ }^{\mathrm{E} 2}$, from which the counter-radiation of the atmosphere can be calculated when the constant $(\sigma)$ in the STEFANBOLTZMANN law $\left(R=\sigma T^{4}\right)$ is assumed to be known. This was almost at the time when the work by $\mathrm{EMDEN}^{\mathrm{E} 1}$ was published, which put an emphasis on the significance of observing the radiation of the atmosphere with different water vapour content. My measurements, which were taken at different humidities $\left(0.5\right.$ to $\left.12 \mathrm{~mm}[\mathrm{Hg}]^{\mathrm{E} 4}\right)$, different temperatures $\left(0\right.$ to $\left.30^{\circ} \mathrm{C}\right)$ and at different altitudes above sea level $(0$ to $4420 \mathrm{~m})$, have recently been published by the Smithsonian Institution. ${ }^{2}$ They have led to the following conclusions:

\footnotetext{
${ }^{2}$ Smithsonian Misc. Coll., Vol. 65, No. 3. Washington 1915. Astrophys. Journ. Vol. 37, No. 5, 1913.
} 
Table 1: Effective longwave emission $\left[\mathrm{cal} /\left(\mathrm{cm}^{2} \mathrm{~min}\right)^{\mathrm{E} 4}\right]$ at different temperatures and different values of absolute humidity $(p)^{\mathrm{E} 4}[\mathrm{square}$ brackets in this table are original].

\begin{tabular}{ccccccccccc}
\hline & $p=0 \mathrm{~mm}$ & 1 & 2 & 3 & 4 & 5 & 6 & 8 & 10 & 12 \\
\hline$-30{ }^{\circ} \mathrm{C}$ & 0.135 & {$[0.119]$} & - & - & - & - & - & - & - & - \\
-25 & 0.146 & {$[0.129]$} & - & - & - & - & - & - & - & - \\
-20 & 0.158 & {$[0.140]$} & - & - & - & - & - & - & - & - \\
-15 & 0.171 & 0.152 & {$[0.141]$} & - & - & - & - & - & - & - \\
-10 & 0.185 & 0.165 & {$[0.152]$} & {$[0.143]$} & - & - & - & - & - & - \\
-5 & 0.199 & 0.177 & 0.164 & 0.154 & {$[0.142]$} & - & - & - & - & - \\
0 & 0.215 & 0.192 & 0.178 & 0.167 & 0.154 & {$[0.146]$} & {$[0.140]$} & - & - & - \\
5 & 0.231 & 0.207 & 0.193 & 0.180 & 0.168 & 0.157 & 0.150 & {$[0.136]$} & - & - \\
10 & 0.248 & 0.223 & 0.209 & 0.194 & 0.182 & 0.169 & 0.161 & 0.147 & {$[0.137]$} & {$[0.129]$} \\
15 & 0.265 & 0.239 & 0.224 & 0.209 & 0.196 & 0.183 & 0.174 & 0.159 & 0.148 & 0.139 \\
20 & 0.285 & 0.257 & 0.241 & 0.225 & 0.211 & 0.198 & 0.188 & 0.171 & 0.160 & 0.150 \\
25 & 0.305 & 0.275 & 0.258 & 0.242 & 0.227 & 0.213 & 0.202 & 0.184 & 0.172 & 0.161 \\
30 & 0.325 & 0.294 & 0.276 & 0.259 & 0.243 & 0.229 & 0.217 & 0.197 & 0.184 & 0.172 \\
\hline
\end{tabular}

(I) The variation of the counter-radiation in the lower layers of the atmosphere is primarily caused by temperature and humidity variations.

(II) The counter-radiation of the atmosphere is almost proportional to the fourth power of absolute temperature at the observation station.

(III) The dependence of the counter-radiation on vapour pressure can be expressed by the exponential formula:

$E_{\alpha}^{20}=K-C \cdot 10^{-\gamma p}\left(0.5<p<12 \mathrm{~mm}[\mathrm{Hg}]^{\mathrm{E} 4}\right)$

where $K=0.434, C=0.158$ and $\gamma=0.069 . E_{\alpha}^{20}$ is the counter-radiation of the atmosphere at $20{ }^{\circ} \mathrm{C}$.

(IV) An increase in vapour pressure causes a decrease in the effective terrestrial radiation in any layer of the atmosphere. The relative decrease is much larger for large than for small zenith angles.

(V) The observations suggest that the dry atmosphere $\left(p<1 \mathrm{~mm}[\mathrm{Hg}]^{\mathrm{E} 4}\right)$ has a considerable radiation potential: At an altitude of $4400 \mathrm{~m}$, radiation is almost $50 \%$ of the radiation of a black body of the same temperature as measured at the observation location.

(VI) Variations in the transmission of the atmosphere for shortwave radiation only have a minor influence on the magnitude of the counter-radiation of the atmosphere.

By means of II and III, it is possible to calculate the counter-radiation of the atmosphere and also the effective terrestrial radiation for any corresponding value of temperature and humidity. In order to do so, I have transformed the equation in III, which is valid for a temperature of $20^{\circ} \mathrm{C}$, into the following:

$$
E_{\alpha}^{20}=K-C \cdot 10^{-\beta \rho}
$$

where $\rho$ denotes absolute humidity (in grams per cubic meter) ${ }^{\mathrm{E} 4}$. $K$ and $C$ have the same values as before. For $\beta$ a value of 0.071 is found, which only slightly differs from $\gamma$. We now base ourselves on the relationship found (II) and assume that the radiation can generally be expressed by the equation:

$$
E_{\alpha}=\frac{T^{4}}{293^{4}}\left[K-C \cdot 10^{-\beta \rho}\right]
$$

The observations are consistent with this relationship. Starting from equation (4), I have composed Table 1, where one can find the effective terrestrial radiation for temperatures between $+30{ }^{\circ} \mathrm{C}$ and $-30{ }^{\circ} \mathrm{C}$ and for vapour pressures between 0 and $12 \mathrm{~mm}[\mathrm{Hg}]$. The extension of the temperature interval to temperatures between $0{ }^{\circ} \mathrm{C}$ and $-30{ }^{\circ} \mathrm{C}$, which could not be verified by the observations in Algeria and California, could be verified under certain conditions by the measurements in Abisko in Lappland. I will return to these observations later.

3. The part of atmospheric radiation that is due to water vapour is a function of the total water vapour contained in the atmosphere above the observation location. The content of water vapour near the Earth's surface is significant only as a measure for the total vapour amount. If this amount - which I will call the 'integrated water vapour' - was a function entirely determined by the absolute humidity on the ground, and only a function of that, and if the temperature distribution in the atmosphere was always the same, the observed values could be expected to agree very closely with the values of temperature, pressure and radiation given in Table 1. However, these conditions are only approximately fulfilled. It is true, of course, that the integrated water vapour seems to be in proportion to the humidity near the ground, if longer time intervals are taken into consideration. Still, the constant of proportionality underlies considerable random variation. 
When using HANN's ${ }^{\mathrm{E}}$ equation for the decrease in water vapour pressure with height $(h)$ :

$$
p_{h}=p_{0} \cdot 10^{-\frac{h}{6500}}
$$

or SÜRING's equation ${ }^{\mathrm{E} 6}$, which is true for the free atmosphere:

$$
p_{h}=p_{0} \cdot 10^{-\frac{h}{6000}\left(1+\frac{h}{20000}\right)}
$$

we find, since the density can be assumed proportional to pressure with sufficient accuracy:

$$
Q=\int_{0}^{\infty} \rho_{h} d h=K \cdot p_{0}
$$

where $Q$ denotes the integrated water vapour, $p_{0}$ the vapour pressure at the observed location and $K$ a constant [not the same $K$ as in Sect. 2.].

The quantity $Q$ determines the radiation due to the water vapour. If the temperature of the atmosphere was constant, the vertical distribution of water vapour would not matter for the counter-radiation observed on the ground. However, if we examine the dependence of radiation on the vapour pressure $p_{0}$ on the ground, we find that the radiation fluctuates around a certain mean value, even if the vapour pressure as well as temperature are constant, which is partly caused by the fact that the just defined constant $K$ is subject to certain fluctuations. On a diagram with the quantity $K p_{0}$ on the $x$-axis (where at first $K$ is chosen arbitrarily), and the corresponding values of the counter-radiation in the atmosphere on the $y$ axis, we can plot a continuous curve using the mean values of radiation as I have shown. The temperature is assumed to be constant, i.e., the radiation values are reduced to a certain temperature $T$ by means of the relationship II. Now, the individual radiation values differ from the plotted curve by $\pm \delta$ on average, which we call the mean [absolute] variation amplitude. This amplitude $\delta$ corresponds to a certain variation of the quantity $K$ $p_{0}$, which we can assume to result from the variation of the 'constant' $K$, since $p_{0}$ is given. We will call this mean amplitude $\gamma$ [not the same $\gamma$ as in Sect. 2.], which is expressed in percent of $K$.

4. Now the question arises, to what extent this mean amplitude $\gamma$, which can be calculated from radiation measurements, is of a similar or of the same magnitude as the mean amplitude $\gamma_{1}$ comprised in $K$. If it turned out that $\gamma$ was much larger than $\gamma_{1}$, one would have to conclude that the fluctuations of the radiation in the atmosphere were caused by the variation in water vapour content only to a minor extent, and that other variations of unknown origin played a significant role. However, if $\gamma$ and $\gamma_{1}$ were found to be very similar, we would have strong support of the view already given in the summary of my results, namely that, with constant temperature, the variation in water vapour content was crucial for the variation in counter-radiation. [Table 2]
5. Since, in my view, answering this question is of major significance for assessing the general validity of the relationship found between radiation and humidity, I have made use of the excellent observations by the U.S. Weather Bureau by means of balloon ascents at locations close to my observations locations in order to calculate $\gamma_{l}$. These balloon ascents took place on the island Santa Catalina ${ }^{\mathrm{E} 7}$ near Avalon ${ }^{\mathrm{E} 7}$, while my observations were carried out in Lone Pine ${ }^{\mathrm{E} 7}(1140 \mathrm{~m})$, Lone Pine Canyon ${ }^{\mathrm{E} 7}(2500 \mathrm{~m})$, on the summits of Mt. Whitney $^{\mathrm{E} 7}(4400 \mathrm{~m})$, Mt. San Gorgonio ${ }^{\mathrm{E7}}$ (3500 m), Mt. Wilson ${ }^{\mathrm{E} 7}(1800 \mathrm{~m})$ and in Indio ${ }^{\mathrm{E} 7}(0 \mathrm{~m})$ at almost the same time. The distances between Avalon and the observation locations mentioned are between 50 and $250 \mathrm{~km}$. It is therefore hardly allowed to draw any conclusions about the integral water vapour $Q$ from the ascents, and to relate them to the locations where radiation measurements were carried out. However, it seems to be of interest to calculate $K$ from the balloon observations for each observation series, and then to determine the mean variation of $K$. This variation amplitude $\gamma_{1}$, which is true for Avalon in the first place, can be compared with better justification to the variation amplitude $\gamma$, determined by radiation measurements. The values of absolute humidity (grams per cubic meter), which result from the balloon ascents, have been compiled by Dr. BLAIR ${ }^{\mathrm{E} 8}$ in Table $2 .^{3}$ The values in the table can be used to calculate $Q$ and $K$ for each day either graphically or by summing the rows, which seems to be sufficiently accurate. I have calculated $K$ for the altitudes of $1500 \mathrm{~m}, 3000 \mathrm{~m}$ and $5000 \mathrm{~m}$ and found the values given in Table 3 . The mean variation is given at the end of each column. It shows that the variation decreases with increasing height.

The mean variation of radiation is calculated for different intervals of vapour pressure as presented in Table 4. The mean deviation from the curve is $\pm 0.0115 \mathrm{cal} /\left(\mathrm{cm}^{2}\right.$ $\min )\left[ \pm 8.02 \mathrm{~W} / \mathrm{m}^{2}\right]^{\mathrm{E} 4}$ for Lone Pine ${ }^{\mathrm{E} 7}(1140 \mathrm{~m})$, $\pm 0.010\left[ \pm 6.97 \mathrm{~W} / \mathrm{m}^{2}\right]$ for Mt. San Gorgonio ${ }^{\mathrm{E} 7}$ and Lone Pine Canyon ${ }^{\mathrm{E} 7}(3000 \mathrm{~m})$ and $\pm 0.0163\left[ \pm 11.37 \mathrm{~W} / \mathrm{m}^{2}\right]$ for Mt. Whitney ${ }^{\mathrm{E} 7}(4420 \mathrm{~m})$. For comparison, the variation amplitude for Bassour (Algeria) was 0.0113 [7.88 $\left.\mathrm{W} / \mathrm{m}^{2}\right]$. This mean deviation, which is between 5 and 10 percent of the actual radiation, corresponds to a variation $\gamma$ given in the table. For comparison, Table 5 shows the variation of $\gamma$ and $\gamma_{1}$ for almost identical altitudes above sea level.

The table shows that the agreement between $\gamma$ and $\gamma_{1}$ is remarkably good for all stations except for Mt. Whitney and Mt. San Gorgonio. For the latter stations, the variation of radiation is much larger than would be expected from the variation of $K$ for these altitudes in the free atmosphere. This is probably largely due to the fact that these stations were located above the snow line, which meant that the evaporation on the snow surface resulted in an increase in the variation of $K$. Here, the actual

$\overline{{ }^{3} \text { Monthly Weather Review, July 1914, p. } 410 .{ }^{\text {E8 }} \text { ANGSTRÖM, A Study of the }}$ Radiation etc., p. 107 E3 $^{\mathrm{E}}$ 
Table 2: Absolute humidity $\left(\mathrm{g}\right.$ per $\left.\mathrm{m}^{3}\right)$ at different altitudes, Avalon, California, 1913.

\begin{tabular}{|c|c|c|c|c|c|c|c|c|c|c|c|c|}
\hline \multirow[b]{2}{*}{ Day } & \multicolumn{12}{|c|}{ Altitude (m) } \\
\hline & 34 & 500 & 1000 & 1500 & 2000 & 2500 & 3000 & 3500 & 4000 & 4500 & 5000 & 6000 \\
\hline 23 July & 12.651 & 10.109 & 9.248 & 6.942 & 5.597 & 4.495 & 3.354 & 2.291 & 1.608 & 1.106 & 0.793 & 0.415 \\
\hline 24 July & 11.363 & 9.740 & 8.808 & 7.562 & 4.993 & 3.871 & 2.976 & 2.329 & 1.820 & 1.441 & 1.162 & - \\
\hline 27 July & 11.949 & 9.687 & 8.708 & 7.288 & 5.003 & 2.852 & 1.661 & 1.301 & 1.064 & 0.839 & 0.581 & 0.289 \\
\hline 28 July & 10.813 & 8.755 & 7.980 & 5.330 & 3.642 & 2.985 & 2.429 & 1.480 & 1.0115 & 0.698 & 0.516 & 0.272 \\
\hline 29 July & 9.933 & 9.372 & 8.913 & 7.645 & 4.711 & 3.056 & 1.964 & 1.163 & 0.674 & 0.384 & 0.265 & 0.112 \\
\hline 1 Aug & 15.210 & 12.077 & 9.369 & 8.072 & 6.661 & 5.459 & 4.739 & 4.268 & 3.367 & 2.302 & 1.662 & 0.831 \\
\hline 2 Aug & 15.817 & 13.928 & 7.750 & 5.828 & 5.657 & 5.255 & 3.986 & 2.781 & 1.840 & 1.243 & 0.922 & 0.476 \\
\hline 3 Aug & 15.199 & 12.014 & 4.205 & 2.925 & 2.850 & 2.541 & 2.109 & 1.560 & 1.178 & 0.898 & - & - \\
\hline 7 Aug & 14.482 & 13.979 & 6.274 & 2.631 & 1.521 & 1.256 & 1.353 & 1.300 & 1.065 & 1.299 & 1.362 & 0.432 \\
\hline 8 Aug & 12.838 & 11.342 & 11.336 & 9.476 & 7.983 & 6.572 & 5.055 & 3.961 & 3.278 & 2.806 & 2.368 & 1.623 \\
\hline
\end{tabular}

\begin{tabular}{|c|c|c|c|c|c|c|c|c|c|c|c|c|c|}
\hline \multirow[b]{2}{*}{ Day } & \multicolumn{13}{|c|}{ Altitude (m) } \\
\hline & 7000 & 8000 & 9000 & 10000 & 11000 & 12000 & 13000 & 14000 & 15000 & 16000 & 17000 & 18000 & 19000 \\
\hline 23 July & 0.207 & 0.095 & 0.055 & 0.034 & 0.024 & 0.019 & 0.013 & 0.008 & 0.004 & 0.004 & 0.003 & 0.003 & 0.004 \\
\hline 27 July & 0.118 & 0.040 & 0.017 & 0.009 & 0.006 & 0.003 & 0.003 & 0.003 & 0.002 & 0.001 & 0.001 & 0.002 & 0.003 \\
\hline 28 July & 0.125 & 0.051 & 0.023 & 0.010 & 0.005 & 0.003 & 0.003 & 0.003 & 0.001 & 0.001 & 0.001 & 0.002 & 0.002 \\
\hline 31 July & 0.118 & 0.062 & 0.034 & 0.014 & 0.007 & 0.004 & 0.002 & 0.002 & 0.003 & 0.002 & 0.001 & 0.002 & 0.002 \\
\hline $1 \mathrm{Aug}$ & 0.406 & 0.199 & 0.103 & 0.054 & 0.026 & 0.013 & 0.009 & 0.012 & 0.011 & 0.007 & 0.005 & 0.004 & 0.004 \\
\hline 2 Aug & 0.235 & 0.105 & 0.055 & 0.021 & 0.008 & 0.003 & 0.003 & 0.003 & 0.004 & - & - & - & - \\
\hline 8 Aug & 1.180 & 0.655 & 0.346 & 0.215 & 0.124 & 0.077 & 0.055 & 0.033 & - & - & - & - & - \\
\hline Mean & 0.296 & 0.148 & 0.077 & 0.043 & 0.025 & 0.017 & 0.012 & 0.009 & 0.005 & 0.003 & 0.002 & 0.003 & 0.003 \\
\hline
\end{tabular}

\begin{tabular}{lccccccccccccc}
\hline & \multicolumn{10}{c}{ Altitude $(\mathrm{m})$} \\
\cline { 2 - 13 } Day & 20000 & 21000 & 22000 & 23000 & 24000 & 25000 & 26000 & 27000 & 28000 & 29000 & 30000 & 31000 & 32000 \\
\hline 23 July & 0.004 & 0.006 & 0.007 & 0.010 & 0.014 & 0.018 & - & - & - & - & - & - & - \\
24 July & 0.008 & - & - & - & - & - & - & - & - & - & - & - & - \\
27 July & 0.003 & 0.003 & 0.004 & 0.005 & 0.007 & - & - & - & - & - & - & - & - \\
30 July & 0.001 & 0.002 & 0.002 & 0.002 & 0.002 & 0.003 & 0.004 & 0.004 & 0.005 & 0.005 & 0.005 & 0.006 & 0.006 \\
31 July & 0.003 & 0.004 & 0.005 & - & - & - & - & - & - & - & - & - & - \\
1 Aug & 0.006 & 0.006 & 0.007 & 0.008 & - & - & - & - & - & - & - & - & - \\
Mean & 0.004 & 0.004 & 0.008 & 0.006 & 0.008 & 0.010 & 0.004 & 0.004 & 0.004 & 0.005 & 0.005 & 0.006 & 0.006 \\
\hline
\end{tabular}

variation of $\gamma_{1}$ is certainly much larger than calculated from the observations in Avalon. This is indeed the case, as is shown clearly by the tethered balloon ascents carried out by the U.S. Weather Bureau on 3, 4 and 5 August on Mt. Whitney. ${ }^{4}$ If it is allowed to base oneself on such a limited number of observations, one could conclude that here, the variation of $K$ reaches a mean amplitude of 40 to 50 percent, which incidentally almost coincides with the value derived from the [observed] radiation variation. By the way, it is very clear that one has to expect $\gamma$ to be

${ }^{4}$ See: A study of the Radiation of the Atmosphere etc. (1. c.) Fig. 12, p. $142 .^{\mathrm{E} 3}$ larger than $\gamma_{1}$, because for constant temperature on the ground, radiation variation does not only depend on the variation of water vapour content but also, to a greater or lesser extent, on the temperature variation in the higher atmospheric layers.

\section{Counter-radiation of the atmosphere at different altitudes}

6. According to II and III [see Section 2], the radiation of the atmosphere can be calculated for different altitudes if the temperature and humidity distributions are known. 
Table 3: [Calculated values of $K$ for altitudes of $1500 \mathrm{~m}, 3000 \mathrm{~m}$, and $5000 \mathrm{~m}$ ]

\begin{tabular}{lllllllllll}
\hline Time & 23 July & 27 July & 28 July & 30 July & 31 July & 1 Aug & 2 Aug & 8 Aug & Mean & Mean variation $\gamma_{1}$ \\
\hline $\mathrm{K}_{1500}$ & 2.09 & 1.53 & 1.85 & 1.94 & 1.52 & 2.58 & 2.60 & 2.79 & 2.11 & $19 \%$ \\
$\mathrm{~K}_{3000}$ & 1.83 & 2.05 & 1.59 & 1.81 & 2.01 & 2.27 & 2.85 & 1.72 & 2.02 & $14 \%$ \\
$\mathrm{~K}_{5000}$ & 2.24 & 1.97 & 1.98 & 2.16 & 2.47 & 2.06 & 2.09 & 2.90 & 2.23 & $10 \%$ \\
\hline
\end{tabular}

Table 4: [Mean variation of radiation in $\mathrm{cal} /\left(\mathrm{cm}^{2} \mathrm{~min}\right)^{\mathrm{E} 4}$ as a function of water vapour pressure near the ground $p_{0}$ ]

\begin{tabular}{lcccc}
\hline$p_{0}$ & Lone Pine & Bassour & $\begin{array}{c}\text { Mt. San } \\
\text { Gorgonio } \\
\text { and Lone Pine } \\
\text { Canyon }\end{array}$ & Mt. Whitney \\
\hline $0.5-1.0$ & - & - & - & 0.015 \\
$1.0-1.5$ & - & - & - & - \\
$1.5-2.0$ & - & - & 0.007 & 0.014 \\
$2.0-2.5$ & - & - & - & 0.015 \\
$2.5-3.0$ & - & - & 0.010 & 0.014 \\
$3.0-3.5$ & - & - & - & 0.019 \\
$3.5-4.0$ & - & - & 0.009 & 0.021 \\
$3.5-4.5$ & 0.011 & 0.015 & - & - \\
$4.5-5.5$ & 0.013 & 0.014 & 0.017 & - \\
$5.5-6.5$ & 0.010 & 0.019 & 0.009 & - \\
$6.5-7.5$ & 0.012 & 0.010 & - & - \\
$7.5-8.5$ & 0.013 & 0.013 & 0.005 & - \\
$8.5-9.5$ & 0.010 & 0.010 & - & - \\
$9.5-11.5$ & 0.010 & 0.003 & - & 0.0163 \\
Mean & 0.0115 & 0.0113 & 0.0100 & $42 \%$ \\
$\gamma$ & $22 \%$ & $22 \%$ & $16 \%$ & \\
\hline
\end{tabular}

Since the relationship between temperature, humidity, and radiation is given directly by the observations, the result gained by such a calculation can be considered as observational material adjusted for stochastic variation. The radiation of the atmosphere at different altitudes determined in this way is shown in Table 6 , column 4 , where the temperature gradient is set to $0.8^{\circ} \mathrm{C}$ per 100 $\mathrm{m}$ and humidity on the ground to $11 \mathrm{~mm}[\mathrm{Hg}]$. EMDEN $^{\mathrm{E} 1}$ calculated the radiation of the atmosphere at different altitudes under three assumptions: (1) A unit of volume radiates in proportion to the fourth power of its absolute temperature and (2) in proportion to its water vapour content. Furthermore, it is assumed that (3) 10 percent of the Earth's radiation pass the atmosphere. This assumption is based on the calculations carried out by ABBOT and FOWLE $^{\mathrm{E} 9}$. This leads to the values for the counterradiation of the atmosphere or atmospheric radiation at different altitudes given in Table 6 (column 5). Again, the temperature gradient is assumed as $0.8^{\circ} \mathrm{C}$ per $100 \mathrm{~m}$.

A comparison between the values observed by me and those calculated according to EMDEN ${ }^{\mathrm{E} 1}$ shows that the radiation of the atmosphere decreases much more slowly with decreasing water vapour content than EMDEN's approach ${ }^{\mathrm{E} 1}$ suggests. In my view, the difference between observed and calculated values is due to EMDEN's assumption that the air radiates in proportion
Table 5: [Values of $\gamma$ and $\gamma_{1}$ in $\%$ for different altitudes]

\begin{tabular}{lll}
\hline Altitude & $\gamma$ & $\gamma_{1}$ \\
\hline $1500 \mathrm{~m}$ (approx) & 22 & 19 \\
$3000 \mathrm{~m}$ (approx) & 16 & 14 \\
$5000 \mathrm{~m}$ (approx) & 42 & 10 \\
\hline
\end{tabular}

to its absolute water vapour content, which is not in agreement with the actual conditions.

This [EMDEN's] hypothesis would mean that an entirely dry atmosphere would not radiate or absorb in the spectral bands that are considered here (3 to 20 $\mu \mathrm{m})$. This, in fact, contradicts the observations at hand. According to these, EKHOLM ${ }^{5, \mathrm{E} 10}$ calculated that the atmosphere would absorb about 20 percent of the Earth's radiation by considering carbonic acid only. Since absorption is almost complete even in very thin layers, the temperature decrease with altitude is only of minor importance and we can conclude that an entirely dry atmosphere radiates about 20 percent of the radiation of a black body that has the temperature of the observation location, only due to the carbonic acid content. Apart from the absorption by carbonic acid, ozone also strongly absorbs infrared ["ultrarot", at $5 \mu \mathrm{m}$ and $9.8 \mu \mathrm{m}$ ]. ${ }^{6, \mathrm{E} 11}$ Bolometric measurements of the solar spectrum show that the ozone content in the atmosphere considerably absorbs during the cold season, but is of minor importance during the warm season.

Temperature and trace constituents of higher atmospheric layers are so little studied that it is not possible to estimate their emissivity from laboratory studies. According to my observations at elevated stations (3000 to $4400 \mathrm{~m}$ ), the radiation of atmospheric layers at higher altitudes is very important - about 50 percent of a black body of the temperature of the observation location. Evidently, it is not possible to draw conclusions about the nature of the radiation source merely from these observations. Carbonic acid, ozone, and the remaining water vapour (which is indeed small, but strongly absorbing for certain wavelengths) unquestionably play a role. It is an open question whether or not other gases such as hydrocarbons from cosmic or telluric origin also matter. $^{7, \mathrm{E} 12}$

\footnotetext{
${ }^{5}$ Meteorol. Zeitschr. 1902, p. 489-505. E10 $^{6}$

${ }^{6}$ K. ANGSTRÖM, Arkiv för matem. Etc. I, p. 347, 1904. ${ }^{\text {E11 }}$

${ }^{7}$ According to COBLENTZ, the hydrocarbons strongly absorb at wavelengths between 7 and $8 \mu[\mathrm{m}] .{ }^{\mathrm{E} 12}$
} 
Table 6: [Counter-radiation or atmospheric radiation, square brackets in this table provide values in $\left.\mathrm{W} \mathrm{m}^{-2}\right]^{\mathrm{E} 4}$

\begin{tabular}{|c|c|c|c|c|c|}
\hline \multirow[b]{2}{*}{$\begin{array}{l}\text { Altitude } \\
\mathrm{m}\end{array}$} & \multirow[b]{2}{*}{$\begin{array}{l}\text { Temperature } \\
{ }^{\circ} \mathrm{C}\end{array}$} & \multirow[b]{2}{*}{$\begin{array}{c}p \mathrm{~mm} \\
\mathrm{Hg}\end{array}$} & \multicolumn{3}{|c|}{ Atmospheric radiation } \\
\hline & & & $\begin{array}{l}\text { obs. Angström g cal / } \\
\mathrm{cm}^{2} \min \left[\mathrm{W} \mathrm{m}^{-2}\right]\end{array}$ & $\begin{array}{l}\text { calc. acc. to Emden } \mathrm{g} \text { cal / } \\
\mathrm{cm}^{2} \min \left[\mathrm{W} \mathrm{m}^{-2}\right]\end{array}$ & $\begin{array}{l}\text { Difference } \mathrm{g} \text { cal / } \\
\mathrm{cm}^{2} \min \left[\mathrm{W} \mathrm{m}^{-2}\right]\end{array}$ \\
\hline 0 & +25 & 11.0 & $0.44[307]$ & $0.48[335]$ & $-0.04[-28]$ \\
\hline 1000 & +17 & 6.8 & $0.37[258]$ & $0.34[237]$ & $+0.03[+21]$ \\
\hline 2000 & +9 & 4.1 & $0.31[216]$ & $0.225[157]$ & $+0.085[+59]$ \\
\hline 3000 & +1 & 2.4 & $0.25[175]$ & $0.135[94]$ & $+0.115[+81]$ \\
\hline
\end{tabular}

Table 7: Effective longwave emission [in Abisko, in cal $\left./\left(\mathrm{cm}^{2} \mathrm{~min}\right)^{\mathrm{E} 4}\right]$. Wind speed larger than $3 \mathrm{~m} / \mathrm{s}$.

\begin{tabular}{|c|c|c|c|c|c|c|}
\hline \multirow[b]{2}{*}{ Day } & \multirow[b]{2}{*}{ Time [hour, minute] } & \multirow[b]{2}{*}{ Temperature $\left[{ }^{\circ} \mathrm{C}\right]$} & \multirow[b]{2}{*}{$p\left[\mathrm{~mm} \mathrm{Hg}^{\mathrm{E} 4}\right]$} & \multicolumn{2}{|c|}{ Emission } & \multirow[b]{2}{*}{ difference } \\
\hline & & & & observed & calculated & \\
\hline \multirow[t]{3}{*}{5 January } & $7 \mathrm{p} 30$ & -14.0 & 1.4 & 0.156 & 0.151 & -0.005 \\
\hline & $9 \mathrm{p} 15$ & -13.3 & 1.2 & 0.148 & 0.153 & +0.005 \\
\hline & $11 \mathrm{p} 10$ & -14.0 & 1.4 & 0.139 & 0.151 & +0.012 \\
\hline \multirow[t]{5}{*}{9 January } & 10a 20 & -9.7 & 2.3 & 0.151 & 0.149 & -0.002 \\
\hline & $2 \mathrm{p} 0$ & -12.6 & 1.5 & 0.141 & 0.158 & +0.017 \\
\hline & $2 \mathrm{p} 20$ & -12.7 & 1.4 & 0.132 & 0.158 & +0.026 \\
\hline & $4 \mathrm{p} 0$ & -13.0 & 1.5 & 0.143 & 0.151 & +0.008 \\
\hline & $4 \mathrm{p} 10$ & -13.2 & 1.4 & 0.145 & 0.151 & +0.006 \\
\hline \multirow[t]{5}{*}{12 January } & $12 \mathrm{p} 10$ & -10.3 & 1.8 & 0.152 & 0.154 & +0.002 \\
\hline & $12 \mathrm{p} 35$ & -10.3 & 1.8 & 0.150 & 0.154 & +0.004 \\
\hline & $1 \mathrm{p} 35$ & -11.7 & 1.4 & 0.160 & 0.155 & -0.005 \\
\hline & $2 \mathrm{p} 35$ & -13.2 & 1.3 & 0.153 & 0.152 & -0.001 \\
\hline & $4 \mathrm{p} 0$ & -13.7 & 1.3 & 0.142 & 0.151 & +0.009 \\
\hline \multirow[t]{2}{*}{18 January } & $9 \mathrm{p} 10$ & -7.7 & 2.3 & 0.147 & 0.154 & +0.007 \\
\hline & $9 \mathrm{p} 35$ & -7.7 & 2.3 & 0.143 & 0.154 & +0.011 \\
\hline Mean & & -11.8 & 1.62 & 0.147 & 0.153 & +0.006 \\
\hline
\end{tabular}

One may question the existence of atmospheric radiation at higher levels and ask whether the apparent radiation is at least partly caused by the reflection of thermal radiation from layers below on solid particles in layers above. However, this seems unlikely, because measuring the transmission of the atmosphere for short wavelengths (solar radiation) during daytime has shown that substances and larger diffusing particles are obviously absent from the higher layers. The existing diffusion can well be explained by the diffusing influence of molecules according to RAYLEIGH - or maybe more correctly by the influence of density variations according to EINSTEIN-KEESOM. ${ }^{8, \mathrm{E} 13}$ Therefore, it seems evident to me that the observed thermal radiation by the atmosphere at stations at higher altitudes is indeed thermal radiation, probably largely caused by atmospheric components other than water vapour.

7. Finally, I will briefly inform about the results of some preliminary observations at the station of Abisko ${ }^{\mathrm{E} 7}$ in Lappland during the polar night. It was my intention to

$\overline{{ }^{8} \text { C.W. OSEEN, Über die Extinktion des Lichtes I u. II. [On the extinction of }}$ light, Parts I and II] Phys. Zeitschr. 1. Juni, 1. Aug. 1916. ${ }^{\text {E14 }}$ F. E. FowLE, The non-selective transmissibility of radiation through dry and moist air. Astrophys. Journ. 38, 1913. ${ }^{\text {E15 }}$ study the radiation of the atmosphere at very low temperature and humidity. These measurements at very low temperature are of particular interest, since the conditions become similar to those that characterise a very dry atmosphere. Abisko is located at $68^{\circ} 21^{\prime} \mathrm{N}$ and $18^{\circ} 47^{\prime} \mathrm{E}$. Between 4 December and 9 January, the sun continuously remains below the horizon. My observations were carried out during January 1916 at temperatures between $0{ }^{\circ} \mathrm{C}$ and $-30{ }^{\circ} \mathrm{C}$ and a vapour pressure of between 0.5 and $3 \mathrm{~mm} \mathrm{Hg}^{\mathrm{E} 4}$. They will be published elsewhere together with the observations of snow temperature and cloudiness, which were carried out at the same time. Here, I will briefly discuss only those observations that were carried out when the sky was completely clear. They are compiled in Tables 7 and 8 together with radiation values calculated according to Table 1 . The table shows that the observed values are generally slightly lower than the calculated values, i.e., slightly lower than the values derived from the observations in California.

The differences are particularly evident for the observations carried out during very calm nights. Conversely, the differences are non-existent or very small during nights with strong breeze. It seems probable that this deviation towards higher values of counter-radiation 
Table 8: Effective longwave emission [in Abisko, in cal $\left./\left(\mathrm{cm}^{2} \mathrm{~min}\right)^{\mathrm{E} 4}\right]$. Wind speed smaller than $1 \mathrm{~m} / \mathrm{s}$

\begin{tabular}{|c|c|c|c|c|c|c|}
\hline \multirow[b]{2}{*}{ Day } & \multirow[b]{2}{*}{ Time [hour, minute] } & \multirow[b]{2}{*}{ Temperature $\left[{ }^{\circ} \mathrm{C}\right]$} & \multirow[b]{2}{*}{$p\left[\mathrm{~mm} \mathrm{Hg}{ }^{\mathrm{E} 4}\right]$} & \multicolumn{2}{|c|}{ Emission } & \multirow[b]{2}{*}{ difference } \\
\hline & & & & observed & calculated & \\
\hline \multirow[t]{3}{*}{14 January } & $8 \mathrm{p} 20$ & -21.5 & 0.7 & 0.125 & 0.142 & +0.017 \\
\hline & $10 \mathrm{p} 0$ & -23.8 & 0.6 & 0.108 & 0.139 & +0.031 \\
\hline & $12 \mathrm{a} 0$ & -24.8 & 0.6 & 0.114 & 0.136 & -0.022 \\
\hline Mean & & -23.4 & 0.63 & 0.116 & 0.139 & +0.023 \\
\hline
\end{tabular}

Table 9: Wind speed $\left[\mathrm{m} / \mathrm{s}\right.$, temperature difference between Vassit Jakko and Vassijaure $\left.\left({ }^{\circ} \mathrm{C}\right)\right]$ and temperature gradients $\left[{ }^{\circ} \mathrm{C} / 100 \mathrm{~m}\right]$ in summer and winter in Arctic regions (Vassijaure $68^{\circ} 25^{\prime} \mathrm{N}, 18^{\circ} 11^{\prime} \mathrm{E}$ )

\begin{tabular}{|c|c|c|c|c|c|c|c|c|}
\hline \multicolumn{3}{|c|}{ January to February } & \multicolumn{3}{|c|}{ November to December } & \multicolumn{3}{|c|}{ June to July } \\
\hline Wind sp. & $\Delta \mathrm{T}$ & $\Delta \mathrm{T} / 100 \mathrm{~m}$ & Wind sp. & $\Delta \mathrm{T}$ & $\Delta \mathrm{T} / 100 \mathrm{~m}$ & Wind sp. & $\Delta \mathrm{T}$ & $\Delta \mathrm{T} / 100 \mathrm{~m}$ \\
\hline $0-1$ & -5.1 & -0.60 & $1-2$ & +0.2 & +0.02 & $1-3$ & 7.2 & 0.84 \\
\hline $1-2$ & +1.0 & +0.12 & $2-3$ & +1.0 & +0.12 & $3-4$ & 6.8 & 0.80 \\
\hline $2-3$ & +3.1 & +0.36 & $3-4$ & +3.8 & +0.45 & $4-5$ & 7.1 & 0.83 \\
\hline $3-4$ & +5.3 & +0.62 & $4-7$ & +5.5 & +0.64 & $5-6$ & 6.4 & 0.75 \\
\hline $4-5$ & +6.1 & +0.71 & $7-9$ & +6.7 & +0.78 & $6-7$ & 7.2 & 0.84 \\
\hline $5-8$ & +6.6 & +0.77 & $>10$ & +7.0 & +0.82 & $7-8$ & 7.7 & 0.90 \\
\hline$\geq 10$ & +6.5 & +0.76 & & & & $\geq 12$ & 7.6 & 0.89 \\
\hline
\end{tabular}

results from the particular temperature and humidity conditions that form during calm and clear winter nights. In these regions, such nights are often characterised by a strong temperature inversion between 50 and $500 \mathrm{~m}$ above ground. Above the cold ground layer, there is a warmer air layer, often with a higher absolute humidity and, as a result, the radiation of the atmosphere will become larger than the value expected based on the observations carried out with temperature and humidity continuously decreasing with altitude. When atmospheric circulation is strong enough to prevent such an inversion, the conditions are similar to those during the brighter season, since the warming of the ground by solar radiation and the subsequent convection result in more even temperature and humidity conditions. A study of the temperature gradient in lower air layers in these northern regions unambiguously shows that there is a close relationship between temperature gradient and wind speed. Here I base myself on the meteorological observations made by E. H. NORINDER in Vassijaure ${ }^{\mathrm{E} 7}(519 \mathrm{~m})$ and in the nearby mountain range Vassit Jakko ${ }^{\mathrm{E} 7}(1372 \mathrm{~m}) .{ }^{9}$ Simultaneous temperature observations for these two locations are available. Furthermore, wind speed measurements are available for Vassijaure. Grouping the temperature difference between Vassijaure and Vassit Jakko (at 8 p.m.) according to the mean wind speed during the day yields the values given in Table 9. The table, and even more distinctly the figure [Fig. 1], show that the temperature gradient on average increases during the winter months (November to February) with increasing wind speed.

\footnotetext{
${ }^{9}$ Appendice aux observations météorologiques suédoises publiées par l'academie royal des science de suède. [Appendix to the Swedish meteorological observations published by the Royal Swedish Academy of Sciences] Vol. 53. 2:ième série: vol. 39, 1911.
}

However, the temperature gradient does not increase infinitely, but seems to approach a threshold, which is almost reached with a wind speed of $6 \mathrm{~m} / \mathrm{s}$. The temperature difference even takes negative values with low wind speed (less than $1.5 \mathrm{~m} / \mathrm{s}$ ), and the negative values become rather significant with still air. The conditions are entirely different during the bright season, when the warming of the ground by solar radiation is a major factor. Table 9 shows that, on average, the temperature difference in June and July is constant for different wind speeds. It has to be noted that this constant value $0.83{ }^{\circ} \mathrm{C}$ per $100 \mathrm{~m}$ - is very close to the threshold value that the temperature gradient approaches with very high wind speeds in November to February. This compilation clearly shows that the atmosphere radiates more strongly in calm winter nights than under circumstances in which wind speed is high or convection is occurring for other reasons. My observations fully agree with this view as the tables [Tables 7 and 8] show.

In summary, the variation of atmospheric radiation can be explained by the variation of temperature and of the water vapour content of the atmosphere. Where a constant relationship between this variation and corresponding variations in the ground layer occurs, one can also expect a relationship between the observed counter-radiation on the one side, and temperature and humidity at the observation location on the other. The more irregular the variations of temperature and humidity in the atmospheric layers above the observation location are, the more uncertain the calculation of the radiation on the basis of temperature and humidity measurements on the ground will become. My observations in Algeria and California show that with the then prevailing conditions - an almost clear sky and relatively little humidity - 


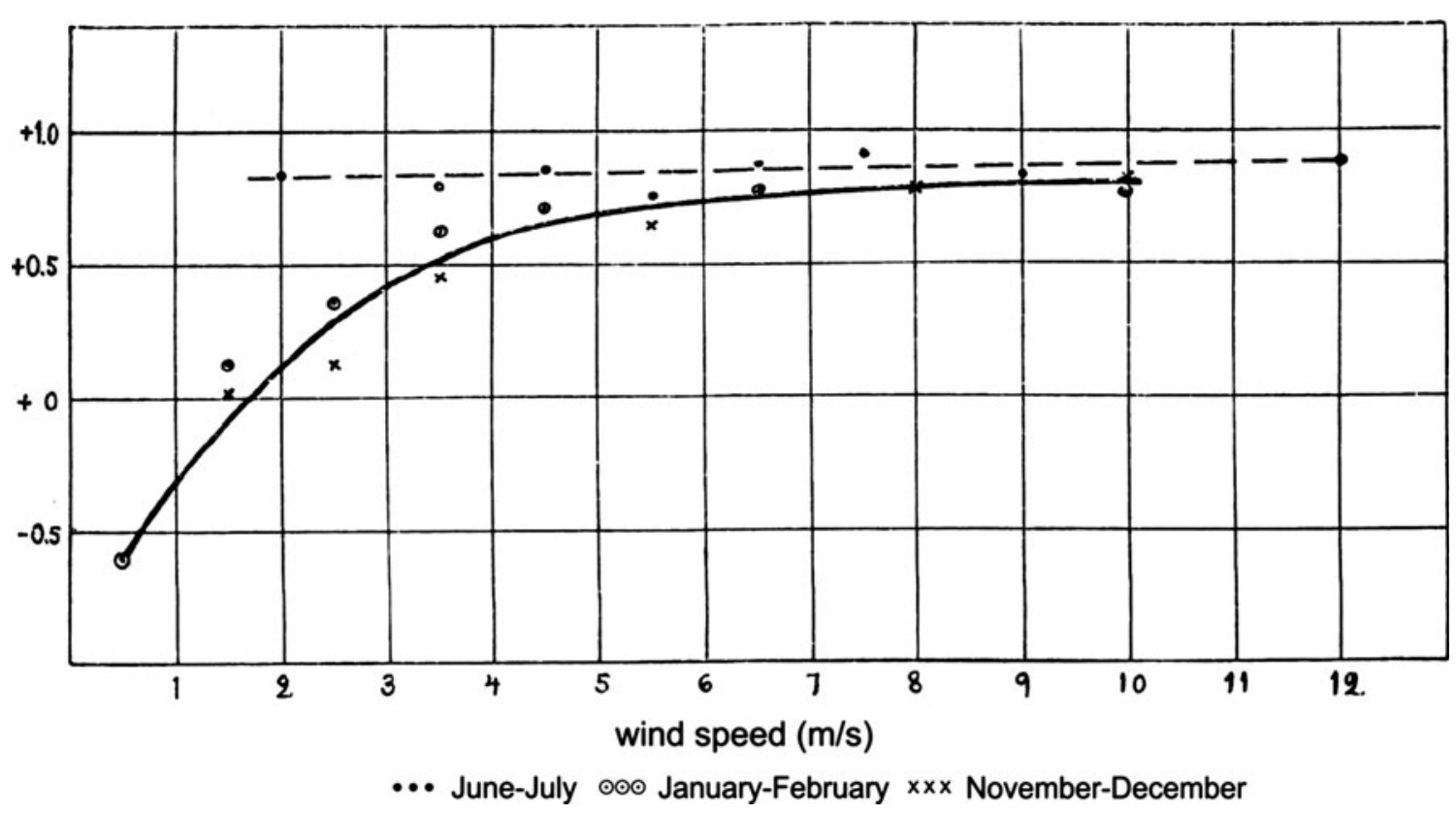

Figure 1: Wind speed and temperature gradient [y-axis, in $\left.{ }^{\circ} \mathrm{C} / 100 \mathrm{~m}\right]$ in Arctic regions (Vassijaure).

such a calculation can be done with an accuracy of 5 to 10 percent.

However, these results must be applied to other climatic conditions with some caution. Particularly in winter, atmospheric conditions suggest a larger value of atmospheric radiation than observed in summer. I will continue my studies on this. However, it must be noted that it is of utmost importance to carry out observations regarding this subject at different locations and under different climatic conditions. Only after such observations are at hand in a larger number, it will be possible to base on them a deeper study about radiation within the atmosphere and its influence on temperature as the most important climatic factor. EMDEN has provided the theoretical basis for such a study.

\section{Endnotes}

E1 HuMPHREYS, W. J. 1909: Vertical temperature gradient of the atmosphere, especially in the region of the upper inversion. - Astrophys. J. 29, 14-32.

GOLD, E., 1909: The isothermal layer of the atmosphere and atmospheric radiation. - Proc. R. Soc. Lond. 82A, 43-70.

EMDEN, R. 1913: Über Strahlungsgleichgewicht und atmosphärische Strahlung. - Sitzungsber.

K. Bayer. Akad. Wissen. Math-Phys Kl. 1913, 55-142. HUMPHREYS and GOLD in 1909 had attempted to apply the theory of radiative equilibrium to the Earth atmosphere in order to explain the "upper inversion", i.e., the tropopause, but found an isothermal atmosphere. EMDEN found more realistic temperature profiles by assuming that water vapour is not a grey body but has different characteristics in the shortwave and long- wave. He also found that the layer close to the Earth's surface must be convective and interpreted the tropopause as the transition between the two equilibria. The discussion was continued by HERGESELL and others. With the advent of numerical methods in meteorology, MANABE and STRICKLER calculated the radiativeconvective equilibrium.

MANABE, S., R. F. STRICKLER, 1964: Thermal Equilibrium of the Atmosphere with a Convective Adjustment. - J. Atmos. Sci. 21, 361-385.

E2 The effective terrestrial radiation is the effective thermal radiation emitted from the measuring instrument at ambient surface air temperature. Knowing this temperature the counter-radiation, or the longwave downward radiation, of the atmosphere can be determined.

E3 ANGSTRÖM, A., 1915: A study of the radiation of the atmosphere. - Smithsonian Misc. Coll. 65 (1916), No. $3.55 \mathrm{pp}$.

ANGSTRÖM, A., 1913: Studies of the nocturnal radiation to space. - Astrophys. J. 37(5), 305-321.

E4 The paper uses units that are different from today's SI standard: $1 \mathrm{~mm} \mathrm{Hg}$ equals $1.333 \mathrm{hPa}, 1 \mathrm{cal} /\left(\mathrm{cm}^{2} \mathrm{~min}\right)$ equals $697.3 \mathrm{~W} \mathrm{~m}^{-2}$. Angström uses [rho] for humidity expressed in grams per cubic meter and $p$ for humidity expressed as vapour pressure in $\mathrm{mm} \mathrm{Hg}$. He uses the term absolute humidity for both.

E5 HANN, J., 1883: Handbuch der Klimatologie. Engelhorn, Stuttgart.

E6 SÜRING, R., 1900: Die Verteilung des Wasserdampfes. - In: ASSMANN, R., A. BERSON (Eds.), Wissenschaftliche Luftfahrten. Dritter Band. Zusammenfassung und Hauptergebnisse. Vieweg und Sohn (Braunschweig). 
E7 Map of the locations mentioned in the text.
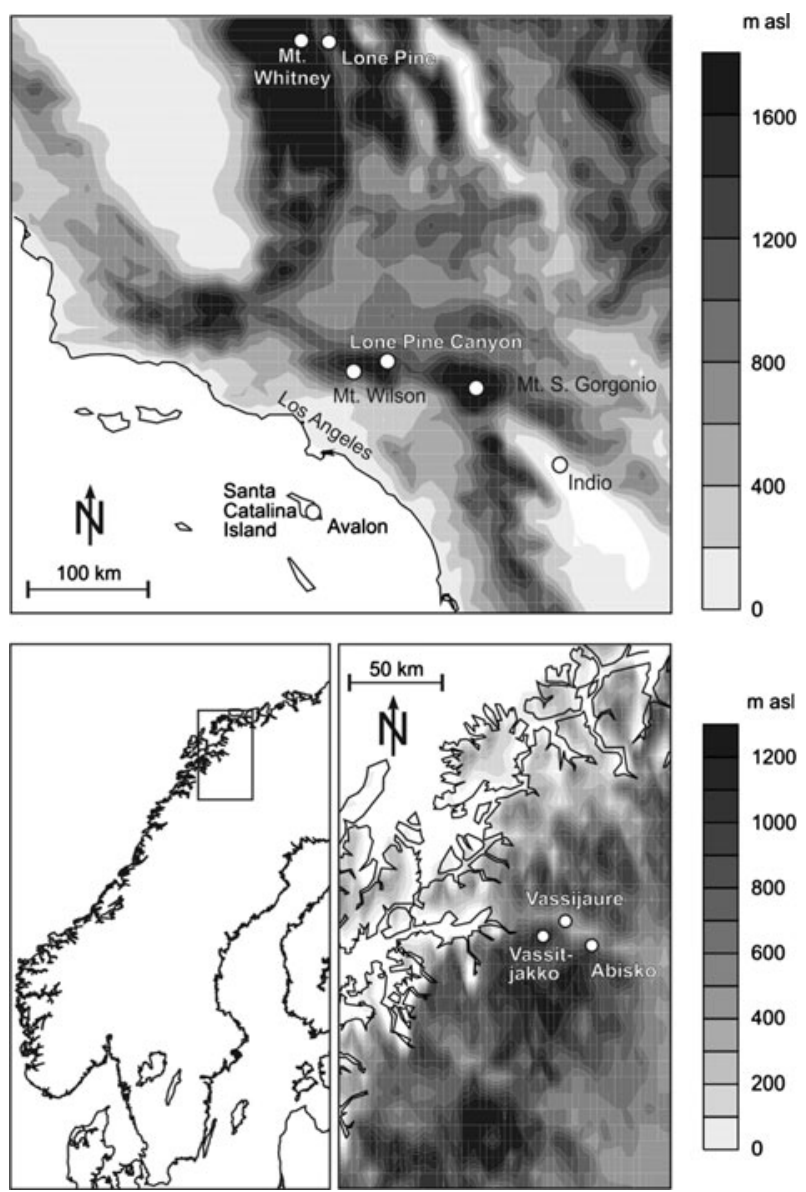

E8 WiLliam RichaRdS BLAIR (7 November 1874 - 2 September 1962), American aerologist, who is credited with the invention, in 1937, of radar.

BLAIR, W.R., 1914: Free-air data in southern Calofornia, July and August 1913. - Mon. Wea. Rev. 42, 410-426.

E9 The reference is not given. The sentence might refer to:
ABBOT, C.G., F.E. Fowle, 1908: Income and Outgo of Heat from the Earth, and the Dependence of Its Temperature Thereon. - Annals of the Astrophysical Observatory of the Smithsonian Institution 2, 159176.

E10 EKHOLM, N., 1902: Über Emission und Absorption der Wärme und deren Bedeutung für die Temperatur der Erdoberfläche. - Meteorol. Z. 19, 1-26, 489505.

E11 ANGSTRÖM, K., 1904: Über das ultrarote Absorptions spectrum. - Arkiv för Matematik 1, 347-394.

E12 WILLIAM COBLENTZ (1873-1962), US physicist and astronomer, pioneer of infrared spectroscopy. The exact reference is not given, but might be: COBLENTZ, W., 1905: Investigations of Infra-Red Spectra. - Carnegie Institution of Washington, Washington, D.C. (3 Vols.).

E13 The theory of molecular scattering was developed from the mid 19th century onwards by JOHN TYNDALL, LORD RAYLEIGH, ALBERT EINSTEIN, MARIAN SMOLUCHOWSKI, WILLEM HENDRIK KEESOM and others. Below are two of many publications on the topic:

STRUTT, J. [Lord Rayleigh], 1899: On the transmission of light through an atmosphere containing small particles in suspension, and on the origin of the blue of the sky. - Phil. Mag. Series 5 47, 375394.

EINSTEIN, A., 1910: Theorie der Opaleszenz von homogenen Flüssigkeiten und Flüssigkeitsgemischen in der Nähe des kritischen Zustandes. - Annalen der Physik 33, 1275-1299.

E14 OSEEN, C. W. 1916: Über die Extinktion des Lichtes [Parts I and II]. - Phys. Zeitschr. 17, 233-235 and 341-343 [reference could not be consulted]

E15 FOWLE, F. E., 1913: The non-selective transmissibility of radiation through dry and moist air. Astrophys. J. 38, 392-406. 